Alma Mater Studiorum - Università di Bologna DEPARTMENT OF ECONOMICS

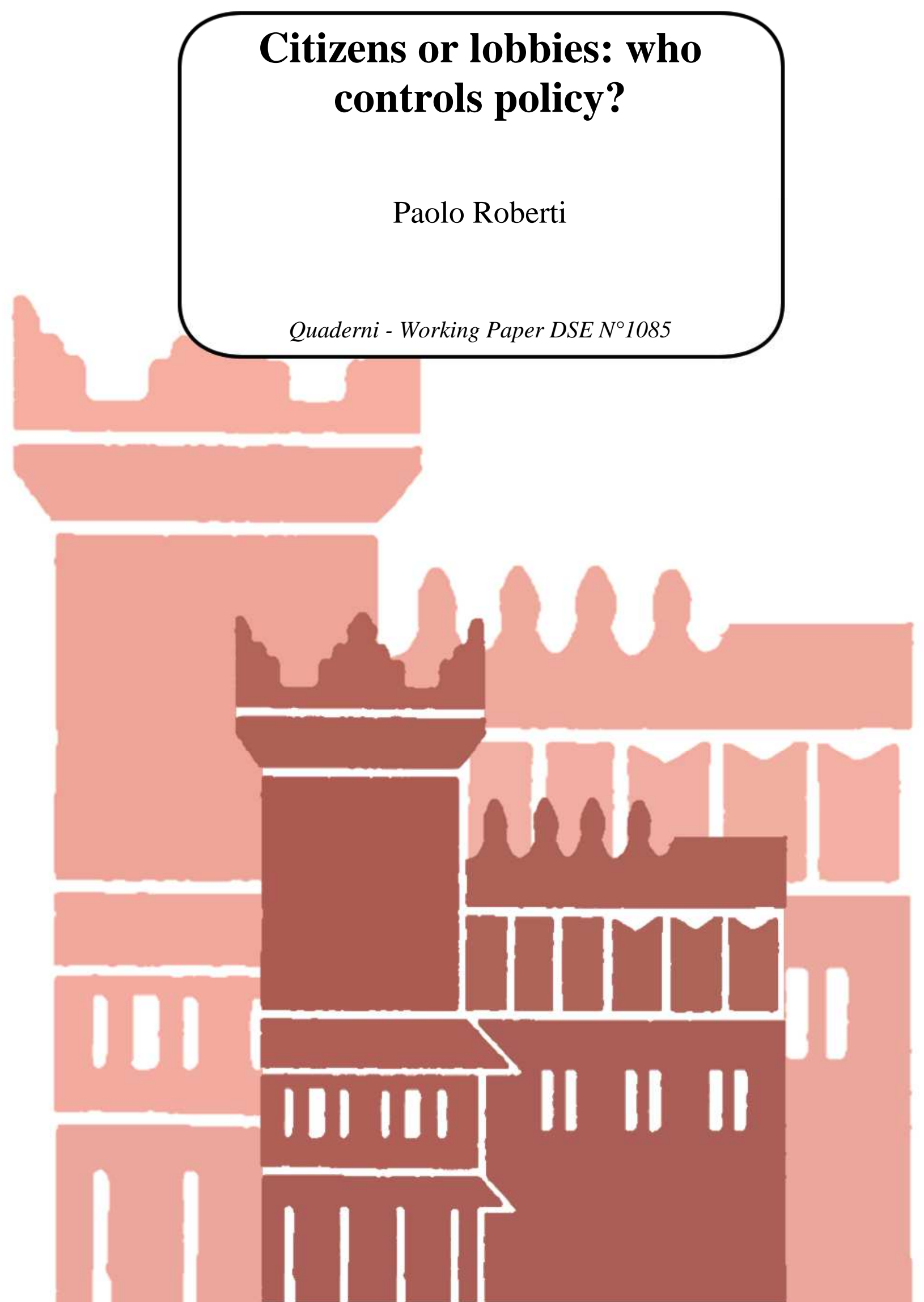




\title{
Citizens or lobbies: who controls policy?*
}

\author{
Paolo Roberti ${ }^{\dagger}$
}

Draft: September 2016

\begin{abstract}
This paper analyses a model of electoral competition with lobbying, where candidates hold private information about their willingness to pander to lobbies, if elected. I show that this uncertainty induces risk-averse voters to choose candidates who implement policies biased in favor of the lobby. Increasing the prior probability of non-pandering candidates can increase the effect of lobbying. If, however, the cost of running for office is sufficiently large, there is no effect of lobbying on policy. The model thus demonstrates that uncertainty on the influence of special interests can lead to large effects of lobbying on policy.
\end{abstract}

JEL-Classication: D72, D74, D78

Keywords: voting, lobbying, citizen-candidate

A central theme in the ongoing debate on lobbying is the influence of special interest groups on elected politicians. Large parts of electoral campaigns are devoted to either showing that a candidate cannot be trusted due to the controlling influence of special interests, or on the contrary, that a candidate can be trusted because she will not pander to lobbies. For example, during the 2016 US Presidential campaign the New York Times Editorial Board warned Hillary Clinton that her level of trustworthiness among voters was

*Acknowledgements: I am grateful to Antonio Nicolò, Andrea Mattozzi, Arnaud Dellis, Sandro Brusco, Jörgen Weibull, Tim Besley, Stefano Bolatto, Giuseppe Pignataro, Elena Lucchese and all the participants of the Fourth Workshop on Institutions, Individual Behaviour and Economic Outcomes in Alghero, Italy, the 2014 Political Economy Workshop in Milan, Italy, the 2014 ASSET conference, and the seminar in Boğaziçi University, Istanbul, Turkey, for helpful comments and suggestions.

${ }^{\dagger}$ Postdoctoral research fellow, Department of Economics, University of Bologna, Piazza Scaravilli 2, 40126 Bologna, Italy. E-mail: paolo.roberti3@unibo.it 
weak, when dealing with the Wall Street lobby. ${ }^{1}$ The debate at hand hinges on an inherent uncertainty faced by voters. While candidates often promise that their concerns are driven solely by policy, it is difficult to predict how they will react to offers made by special interest groups, once in office. Indeed, citizens often express disappointment in their elected representatives' decisions precisely on issues affected by lobbying. For example, a recent poll by CBS News/New York Times documented that $59 \%$ of Americans felt angry and disappointed by the results of a Senate vote which struck down a bipartisan measure for expanding background checks on gun owners, a topic that was subject to extensive lobbying by the National Rifle Association. Republican (86\%), Democratic (95\%) and Independent (83\%) voters all favored this policy. ${ }^{2}$ Moreover, multiple polls conducted by Gallup show that, when American voters are asked whether they think their congressional representatives focus on the needs of special interest groups or the needs of their constituents, half of the respondents answer special interests. ${ }^{3}$ This range of responses suggests that elected politicians vary in their behavior with special interest groups, or that some voters are not well informed about the linkages between their representatives and lobbies. Theories that investigate lobbying under uncertainty typically assess cases of special interest groups acting before the elections, by providing candidates with campaign contributions. Much of that work focuses on the informational content that lobbying can provide to voters, because special interest groups are assumed to be more informed than voters with regards to candidates' skills. ${ }^{4}$

This paper takes a new approach, analyzing instead a model of lobbying in which rational voters are uncertain about the willingness of a candidate to trade policy for favors from lobbies, if elected. This theory allows for an examination of how uncertainty on the responsiveness to lobbying - which, in reality, is widespread - shapes the impact of special interest groups on policy.

Specifically, I outline a model of lobbying with risk-averse citizens, whose

\footnotetext{
${ }^{1}$ See http://www.nytimes.com/2016/02/26/opinion/mrs-clinton-show-voters-thosetranscripts.html

${ }^{2}$ More information is available at http://www.cbsnews.com/news/poll-59-of-americansunhappy-about-senate-gun-vote/

${ }^{3}$ More information available at http://www.gallup.com/poll/1600/congress-public.aspx

${ }^{4}$ Prat $(2002 a, b)$ and Coate (2004) show, for example, that lobbying reduces voters' welfare, in that either the distortion from lobbying is higher than the informational benefit to voters, or voters anticipate the distortion and some consequently switch to the candidate who does not sell out to special interest groups, thwarting the informational benefit of contributions. Ashworth (2006) shows that if there is an incumbency advantage and lobbies provide campaign contributions, the introduction of public financing of electoral campaigns can have ambiguous effects on voters' welfare. In Sobbrio (2011), lobbies influence voters' decision through biased media.
} 
preferences are distributed on a unidimensional policy space. ${ }^{5}$ Voters cast their vote and elect one politician from the pool of citizens who receives, in turn, a contribution proposal from a lobby, in exchange for a policy more in line with the lobby's preferences. There is uncertainty with regard to two types of citizens: saints and merchants. Saints do not value contributions from lobbies, if elected. They therefore do not pander to the interests of lobbies and simply implement their preferred policy. Merchants, instead, positively value these donations and, if elected, implement a policy which is a compromise between their preferred policy and the lobby's preferred policy. ${ }^{6}$

The main finding of this paper is that lobbying is effective: a lack of information on the responsiveness of politicians to lobbying induces risk-averse voters to elect candidates whose policies are biased in favor of the lobby. Studies on lobbying have generally either found that lobbying elected representatives influences policy, assuming that voters are not rational (Grossman and Helpman (1994)), or that rational voters in equilibrium are able to neutralize the effect of special interest groups (Besley and Coate (2001)). In the latter case, voters anticipate the distortion of lobbying on policy and strategically elect politicians with offsetting preferences who, after being lobbied, carry out policies which are equal to those implemented in a model without lobbying. In the model proposed in this paper, voters instead understand that lobbying distorts policies if the candidate is a merchant. They are, however, unable to tell if a candidate is a merchant or a saint, and thus base their vote on an expected policy. The theory shows that the closer the politician's preferred policy is to the lobby's preferred policy, the lower the uncertainty regarding the policy she implements. For example, uncertainty concerning the relationship between a pro-gun Republican and the National Rifle Association does not overly worry voters, because the behavior of this politician does not change significantly if she panders to the lobby or if she does not. On the contrary, uncertainty with regard to the relationship between a Democrat and the NRA matters more to voters, because it implies a larger variation in the politician's implemented policy. Candidates with larger variance of implemented policies are less appealing to risk-averse voters, who in equilibrium elect a candidate whose expected policy is closer to the lobby's preferred policy, because this implies a lower uncertainty.

\footnotetext{
${ }^{5}$ See Roberti (2014) for a multidimensional model with lobbying with uncertainty on candidates' preferences.

${ }^{6}$ This dichotomy resembles the distinction used by Callander (2008) between policy motivated and office motivated candidates, the difference being that merchants are motivated by a specific perk of office - the lobbying contribution - which is a function of the implemented policy.
} 
Moreover, if the responsiveness of merchants to lobbying decreases, i.e. they value less the contribution from the special interest group, the effect of lobbying is reduced: merchants implement policies which are closer to the policy implemented by saints, reducing the uncertainty on the equilibrium policy. More interestingly, the prior probability of saint types in the population of citizens has non-monotonic effect on the influence of lobbying on policy. If there are only merchants, and the probability of saint types increases, the effect of lobbying on policy grows. Indeed, if there are only merchant types, citizens completely offset lobbying, because they correctly anticipate the implemented policy by the elected politician. Increasing the probability of saints creates uncertainty on the behavior of politicians, and thus on implemented policies. Citizens in equilibrium elect a candidate whose expected policy is biased in favor of the lobby, because it reduces the uncertainty on policies. If instead there is already a large uncertainty on the pool of candidates, because the prior probabilities of merchants and saints are balanced, increasing the probability of saints reduces the effect of lobbying on policy.

Finally, I extend the model by analyzing the endogenous entry of candidates, in order to study how the effect of lobbying on policy is mediated by the incentives for entry into politics of saints and merchants. Citizens can choose to run as candidates, paying a cost of entry. Citizens can use the entry of citizens into the electoral arena as a signal reflecting their responsiveness to lobby contributions. The first result is that there is no equilibrium in which only saint types run for office, while merchants stay out of the race: merchants have higher incentives of entry, because they also value the contribution from lobby. Moreover, the analysis shows that, if the cost of running for office is sufficiently large, there is no effect of lobbying on policy, because only merchants choose to run as candidates. Voters update their beliefs on the type of candidate they face, and they are able to perfectly offset lobbying, because there is no uncertainty on politicians' behavior.

The main results of the paper suggest that uncertainty on the influence of special interests is a key driver of the influence of lobbying on policy. Moreover they show that incentivizing the presence of non-pandering candidates in the electoral race, e.g. by lowering the cost of running for office, can increase the effect of special interest groups on policy.

This study builds on political economy literature investigating the effectiveness of lobbying on policy, dating back to Grossman and Helpman (1994) and Besley and Coate (2001). The main contributions of the present paper to this strand of literature are the introduction of a simple way of creating uncertainty on the potential influence of lobbies and the investigation of its 
consequences in terms of policy and selection of candidates. ${ }^{7}$

This paper also speaks to the literature on citizen-candidates pioneered by Osborne and Slivinski (1996) and Besley and Coate (1997), particularly citizen-candidate models under uncertainty and the work of Grosser and Palfrey (2014), who show that private information on ideal points induces substantial political polarization. The theoretical framework in this paper complements this literature by focusing on uncertainty about the trade-off between a politician's utility from policy and another source of utility, namely contributions from lobbies.

Moreover, by showing that the effect of lobbying on policy is present only when there is uncertainty on the behavior of elected politicians, this theory can help explaining the mixed results observed in the empirical literature on the influence of special interest groups. ${ }^{8}$

Finally, this study documents a new channel through which information on candidates conveyed, for instance by the media, can - removing ex-ante uncertainty on the pool of merchants and saints - increase the power of voters over policy decisions.

\section{The model}

A society is composed by a continuum of citizens represented by set $N$ and a lobby. Each citizen has a preferred policy in the policy space $Q=[0,1]$ and cares about the implemented policy; citizen $i$ 's utility function is

$$
U(q, y, i)=u\left(q, q^{i}\right)+\rho^{i} y
$$

where $q \in Q$ is the implemented policy and and $q^{i}$ is citizen $i$ 's bliss point. Following Besley and Coate (2001) and Felli and Merlo (2006), I assume that function $u\left(q, q^{i}\right)$ is strictly concave in $q$, single-peaked and symmetric around $q^{i}$. In other words, voters are risk averse with respect to policies. The utility

\footnotetext{
${ }^{7}$ In Felli and Merlo's (2006, 2007) rational voter models lobbying affects policy, meaning that there are no equilibria where a very extreme policy is implemented. Their analysis provides an intuition of why politicians would collude with antithetical lobbies, but leaves open the question of how and when citizens can neutralize lobbying.

${ }^{8}$ Extensive empirical work has endeavored to assess the effect of lobby donations on policy; see for example Wright (1990), Stratmann (2002), Bronars and Lott (1997). Ansolabehere, de Figueiredo and Snyder (2003) survey this literature and conclude that lobby contributions do not seem to affect policy. Stratmann (2005) finds just the opposite, through a meta-analysis of the papers surveyed by Ansolabehere, de Figueiredo and Snyder (2003). Recent work focusing on revolving door phenomenons, such as that of Blanes i Vidal, Draca and Fons-Rosen (2012) and Luechinger and Moser (2014), indirectly find large effects of lobbying on political outcomes.
} 
is linear in money, which is denoted by $y$. The only monetary gain from being elected is the lobby's contribution. The responsiveness of citizen $i$ to the lobby's contribution is denoted by $\rho^{i}$. Let $f$ denote the density function that describes the distribution of citizens' bliss points on the policy space $Q$ and $q^{M} \in Q$ the bliss point of the median citizen.

The lobby has the following utility function:

$$
V(q, y)=u\left(q, q^{L}\right)+y
$$

where $q^{L}$ is the lobby's bliss point and $q$ is the implemented policy. The utility of the lobby is linear in money $y$. The lobby is a non-elected political agent who can influence policy through a monetary contribution to the elected politician. Thus, as in Besley and Coate (2001) and Felli and Merlo (2006), I abstract from another source of influence wielded by special interest groups, namely campaign contributions. As mentioned, considerable attention has been devoted in the literature to the issue of uncertainty and lobbying through campaign contributions. I assume here for simplicity that there is only one lobby, although the model can easily be extended to multiple lobbies that compete for influence, as discussed in the section on the extensions of the model. I also assume that the special interest group lobbies for a policy on the left of the policy space: $q^{L}<q^{M}$. This model can thus be applied to an election where a powerful special interest group lobbies for a policy opposed by the majority of citizens.

As in Felli and Merlo (2006), in order to have closed form solutions I assume the concave function $u\left(q, q^{i}\right)$ takes the following form:

$$
u\left(q, q^{i}\right)=-\left(q-q^{i}\right)^{2} .
$$

\section{Uncertainty about citizens' preferences}

I assume that there are two types of citizens, defined by their responsiveness to a lobby's contribution, $\rho^{t}, t \in T:=\{m, s\}$. For simplicity I assume $\rho^{m}=\rho$ and $\rho^{s}=0$, but all results extend to $\rho^{m}>\rho^{s}>0$. Merchants (type $m$ ) care about policy but they also consider lobby contributions, while saints (type $s$ ) are solely policy motivated. Lobby contributions could be considered a bribe, which would imply that merchants are corruptible citizens while saints are honest citizens. However, lobbies commonly offer favors to elected politicians that are permitted by law. Take for example, the revolving door phenomenon, where politicians are hired by the private industries that they regulate, reflecting the existence of a lawful intertemporal exchange of policy 
for money. ${ }^{9}$

Saints are thus uncompromising citizens, who do not trade policy for the favors of special interest groups. The probability of citizen $i$ of being a saint is denoted by $p$. Responsiveness to lobbying is the only private information citizens have. Bliss points of all citizens are common knowledge. They can thus be interpreted as the long-standing positions of citizens, known by voters. The responsiveness to lobbying is instead private information, in that voters observe the pandering of candidates to lobbies only once they are elected to office.

\section{Voting}

The winner of the election is selected according to a Condorcet method, where all citizens run as candidates. Condorcet methods elect the candidate who would win a two-candidate election against each of the other candidates using a plurality vote. Moreover, preferences are single-peaked, therefore the Condorcet winner is the candidate preferred by the median voter. If there is more than one Condorcet winner, ties are broken fairly.

\section{Lobbying}

After being elected, politician $P$ and the lobby bargain over policy $q$ to be implemented, and a monetary transfer $R$ that the lobby gives to the politician. Policy $q$ and transfer $R$ are the result of a Nash bargaining in which the politician has bargaining power $k$ :

$$
\max _{q \in Q, R \geq 0}\left[u\left(q, q^{P}\right)+\rho^{t} R-u\left(q^{P}, q^{P}\right)\right]^{k}\left[u\left(q, q^{L}\right)-R-u\left(q^{P}, q^{L}\right)\right]^{1-k},
$$

such that

$$
\left\{\begin{array}{l}
u\left(q, q^{P}\right)+\rho^{t} R-u\left(q^{P}, q^{P}\right) \geq 0, \\
u\left(q, q^{L}\right)-R-u\left(q^{P}, q^{L}\right) \geq 0 .
\end{array}\right.
$$

The status quo utility of the politician is $u\left(q^{P}, q^{P}\right)$, because with no lobbying the politician would implement her bliss point $q^{P}$, while the status quo utility of the lobby is $u\left(q^{P}, q^{L}\right)$. The utility levels $u\left(q, q^{P}\right)+\rho^{t} R-u\left(q^{P}, q^{P}\right)$ and $u\left(q, q^{L}\right)-R-u\left(q^{P}, q^{L}\right)$ are the gains respectively of the politician and the lobby from the bargaining. The lobbying process defined here includes some of the most relevant cases studied in the lobbying literature. Indeed, in Besley and Coate (2001), the lobbying process is built in such a way that the lobby has all the bargaining power, which corresponds to $k=0$ in this

\footnotetext{
${ }^{9}$ An example which falls in a gray legal area is the release of privileged information by private firms that influence financial investments of politicians, see Eggers and Hainmueller (2014).
} 
model. In Felli and Merlo (2006), the politician receives the entire surplus of the negotiation, which matches the case $k=1$. Parameter $k$ serves the purpose of showing that the results of the model do not depend on specific assumptions on the bargaining power of the politician over the lobby.

Summarizing, the timing of the game is as follows:

1. voters observe the bliss points of candidates and select the winner according to a Condorcet method,

2. the elected politician reveals her type,

3. the politician and the lobby engage in a bargaining over the policy $q$ and lobby's contribution $R$,

4. the politician implements policy $q$ and the lobby makes the monetary transfer $R$ to the politician.

In the next section I analyze the equilibrium of this game, and the conditions under which uncertainty on the influence of lobbying affects the equilibrium policy. In Besley and Coate's (2001) rational voter model all citizens are merchant, and lobbying is ineffective because voters are able to anticipate that special interest groups will distort policy. When voting they do not thus consider the bliss point of the candidate in their utility functions, but rather the policy resulting from lobbying. Hence, in equilibrium voters are able to counteract lobbies by electing a candidate with offsetting policy preferences. The equilibrium policies of a model with lobbying are the same of a model without lobbying.

This result is retained as a special case within the framework analyzed in this paper. If there is no lobbying in the model (e.g. all citizens are saints), the median voter is elected and the equilibrium policy is $q^{M}$, the bliss point of the median voter. If, as in Besley and Coate, there are only merchants, the elected candidate is the citizen who implements $q^{M}$. The elected candidate is not the median citizen, but a candidate with a bliss point larger than $q^{M}$. In this case, lobbying does not affect policy.

I anticipate this basic result in order to define the influence of lobbying. Lobbying influences policy if the equilibrium policy is different from $q^{M}$. When there is uncertainty regarding the type of candidate that voters have before them, lobbying can influence policy in two different ways. It can influence the ex-post policy (i.e. the policy implemented after the politician's type is revealed) or the policy expected by voters before the types are revealed. Uncertainty over the implemented policy once the politician's type 
is revealed is unavoidable (and therefore uninteresting to show) because voters cannot predict the candidates' types: with some probability the ex-post policy will be different from $q^{M}$.

I thus employ an ex-ante perspective, focusing on the policy that voters expect from the elected politician before her type is revealed. More formally, let me denote the implemented policy in equilibrium by type $t$ of candidate $i$ by $q^{* i_{t}}$. Let me define the equilibrium expected policy $\bar{q}^{P}:=p q^{* P s}+(1-$ p) $q^{* P m}$.

Definition 1 Lobbying is effective in equilibrium, if the equilibrium expected policy $\bar{q}^{P}$ is different from the median citizen's preferred policy $q^{M}: \bar{q}^{P} \neq q^{M}$. If $\bar{q}^{P}<q^{M}$ the equilibrium expected policy is biased in favor of the lobby, while if $\bar{q}^{P}>q^{M}$ the equilibrium expected policy is biased against the lobby.

\section{Results}

I find the subgame perfect Nash equilibrium (SPNE) of the game by backward induction. When useful for the intuition, I keep in the notation a general utility from policy $u$.

I first show the outcome of the bargaining game between the elected politician $P$ and the lobby.

Proposition 1 (implemented policy) The implemented policy is a convex combination of the bliss point of the politician, $q^{P}$, and the bliss point of the lobby, $q^{L}$ :

$$
q^{* P_{t}}=\frac{q^{P}+\rho^{t} q^{L}}{1+\rho^{t}} .
$$

The lobby's contribution is the following:

$$
\tilde{R}=k\left[u\left(q^{* P_{t}}, q^{L}\right)-u\left(q^{P}, q^{L}\right)\right]+(1-k) \frac{1}{\rho^{t}}\left[u\left(q^{P}, q^{P}\right)-u\left(q^{* P_{t}}, q^{P}\right)\right],
$$

if $\rho^{t} \neq 0$. The contribution $\tilde{R}$ is zero, if $\rho^{t}=0$.

If the elected politician is a saint, her $\rho^{t}$ is equal to zero, and she implements her bliss point. If the elected politician is a merchant, she caters to the lobby, and the implemented policy is between her bliss point and the bliss point of the lobby: $q^{L}<q^{* P_{t}}<q^{P}$. Moreover, as in Besley and Coate (2001) and Felli and Merlo (2006), the implemented policy has the realistic feature of depending on the bliss points of the lobby and the politician. Indeed, having a moderate or an extremist special interest group, which lobbies the politician, has an effect on the implemented policy. Similarly, 
having a moderate or an extremist politician matters for policy. However, the implemented policy does not depend on the bargaining power $k$. Indeed, the solution of problem (1) with respect to $q$, is equivalent to the maximization of expression $u\left(q, q^{P}\right)+\rho^{t} u\left(q, q^{L}\right)$. The negotiation maximizes the joint surplus of the two players, where the utility from the lobby's policy is weighted by $\rho^{t}$, given that the lobby's contribution is the means by which the lobby transmits its preferences to the politician. In the negotiation, both players are willing to compromise on the policy. For this reason, the farther $q^{P}$ is from $q^{L}$, the larger the distortion of lobbying on policy: $q^{P}-q^{* P_{t}}=\frac{\rho^{t}}{1+\rho^{t}}\left(q^{P}-q^{L}\right)$. The same result holds for the lobby: the farther $q^{P}$ is from $q^{L}$, the greater is the distance of $q^{L}$ from the policy: $q^{* P_{t}}-q^{L}=\frac{1}{1+\rho^{t}}\left(q^{P}-q^{L}\right)$.

The equilibrium contribution distributes the surplus of the bargaining to the two players. If the politician has no bargaining power, $k=0$, all the surplus goes to the lobby. Thus the lobby compensates the politician for the loss incurred in the implementation of $q^{* P_{t}}$, with respect to $q^{P}$, but the politician does not gain anything from the negotiation. If $k=1$, the lobby transfers all its gain from the implementation of $q^{* P_{t}}$ to the politician. This is clear from the indirect utility of the politician:

$$
k \frac{\left(\rho^{t}\right)^{2}}{1+\rho^{t}}\left(q^{P}-q^{L}\right)^{2}
$$

which, differently from the implemented policy, depends positively on the bargaining power of the politician $k$. If $\rho^{t}=0$, the indirect utility is zero, because the politician would implement her bliss point $q^{P}$. The indirect utility is computed in the appendix.

At the voting stage the Condorcet winner is selected. Here citizens try to anticipate the distortion created by the lobby. They do not in fact value the bliss point $q^{P}$ of the politician in their utility function, but rather the implemented policy $q^{* P_{t}}$, internalizing the distortion performed by the special interest group. The lobbying subgame showed that candidates with different responsiveness to the lobby's contribution implement different policies. Therefore, the uncertainty relative to the candidates' responsiveness to the lobby's contribution creates uncertainty relative to their implemented policies. Thus each voter $i$ has the following expected utility from the election of candidate $P$ :

$$
\mathbb{E}\left[u\left(q^{* P_{t}}, q^{i}\right)\right]=-\left(q^{i}-\bar{q}^{P}\right)^{2}-\operatorname{Var}^{P},
$$

where $\bar{q}^{P}$ is the expected policy of candidate $P$, and $\operatorname{Var}^{P}$ is the variance of the implemented policy. The expected policy can be expressed as follows: $\bar{q}^{P}=\frac{1+\rho p}{1+\rho} q^{P}+\frac{\rho(1-p)}{1+\rho} q^{L}$. The variance of the implemented policy by candidate $P$ depends positively on the distance between the candidate's bliss point and 
the lobby's preferred policy:

$$
\operatorname{Var}^{P}=v\left(q^{P}-q^{L}\right)^{2}
$$

where quantity $v$ is defined as follows: $v:=\frac{\rho^{2} p(1-p)}{(1+\rho)^{2}}$. The formula of variance is computed in the appendix. If $q^{P}$ is closer to $q^{L}$, the merchant's implemented policy becomes closer to her bliss point $q^{P}$, which in turn is the policy implemented by the saint, hence the variance associated to $P$ decreases. The closer the politician is to the lobby, the lower the uncertainty as to how she behaves. The section on the extensions of the model shows that this result is robust to different assumptions on the effect of lobbying on policy, e.g. the policy implemented by a merchant is $q^{L}$ or a linear shift from her bliss point.

If there is no uncertainty, (e.g. all candidates are merchants), the Condorcet winner would be the candidate who implements the median voter's bliss point. Such a candidate would have a bliss point $q^{P}$ larger than $q^{M}$ : $\frac{q^{P}+\rho q^{L}}{1+\rho}=q^{M}$. Note that if the responsiveness to lobbying $\rho$ is sufficiently large, there is no candidate $P$ whose preferences for policy offset lobbying: $\frac{1+\rho q^{L}}{1+\rho}>q^{M}$. Thus lobbying would affect policies, no matter what voters do. I exclude this possibility in order to focus the analysis on cases where voters are potentially able to offset lobbying, even if there are only merchants in the pool of candidates. Thus I assume the following upper bound on $\rho$ :

$$
\rho \leq \frac{1-q^{M}}{q^{M}-q^{L}}
$$

When there is uncertainty, the Condorcet winner is not the candidate whose expected policy is the median voter's bliss point: $\bar{q}^{P}=q^{M}$. Indeed, the median voter can increase her utility by electing a candidate whose expected policy is lower than $q^{M}$ because, by having a bliss point closer to $q^{L}$, such candidate exhibits a lower variance of implemented policies.

Proposition 2 (voting equilibrium) The equilibrium expected policy is

$$
\bar{q}^{P}=\frac{(1+\rho p)^{2} q^{M}+\rho^{2} p(1-p) q^{L}}{(1+\rho p)^{2}+\rho^{2} p(1-p)} .
$$

Lobbying is effective, because the equilibrium policy is biased in favor of the lobby: $\bar{q}^{P}<q^{M}$.

The proof is in the appendix.

Thus, lobbying creates uncertainty on the policy implemented by politicians. 
This in turn influences the choice of risk-averse voters, who elect a candidate whose expected policy is biased in favor of the lobby. Clearly, this result holds only if voters are risk-averse. If voters are risk-neutral, lobbying does not affect the implemented policy.

Proposition 3 (comparative statics and voter welfare) The following holds:

(i) If the responsiveness to lobbying $\rho$ of merchants decreases, the distortion of lobbying $q^{M}-\bar{q}^{P}$ shrinks.

(ii) The probability that a citizen is a saint has a non-monotonic effect on the distortion of lobbying: if $p \leq \bar{p}$, then increasing the probability $p$ of saint types amplifies the distortion of lobbying, if $p>\bar{p}$, then increasing $p$ reduces the distortion of lobbying.

(iii) Median voter welfare and the distortion of lobbying have the same comparative statics with respect to $\rho$ and $p$.

The proof is in the appendix.

Decreasing the responsiveness to lobbying reduces the distortion of lobbying, because merchants are more similar to saints in their utility and implemented policies. The probability $p$ has a non-monotonic effect. On one hand, when all citizens are merchants, if the probability of having citizens who are saints becomes positive, the uncertainty on the implemented policy is amplified. Thus voters react to the larger uncertainty, choosing a candidate with expected policy closer to the lobby. On the other hand, when the probability that a citizen is a saint is large, a further increase of $p$ reduces the uncertainty over types, and, consequently, on implemented policies. Therefore, voters choose a candidate whose expected policy is closer to the median voter's bliss point.

\section{Endogenous entry of candidates}

In this section I analyze how the presence of a cost for running for office influences the effect of lobbying on policy. As discussed below, the cost of running for office is a key parameter in the debate on the selection of politicians. The objective of this section is to understand if the entry decisions of saints and merchants are differently affected by the cost of entry. If that is the case, the entry decision can act as a signal to voters. If voters can identify the type of candidate they face, lobbying can potentially be fully offset, because there would be no uncertainty on the implemented policy.

Let me assume that a subset $C \subseteq N$ of citizens can choose to run as candidates. Each citizen $i \in C$ can enter as a candidate paying a non monetary 
cost $c$. The function $\sigma(i, t)$ describes the choice of citizen $i$ with type $t$; if $\sigma(i, t)=1$ citizen $(i, t)$ runs for office, if $\sigma=0$ she does not run. Citizen $i$ 's utility now is the following: ${ }^{10}$

$$
U(q, y, i)=u\left(q, q^{i}\right)+\rho^{i} y-c \sigma .
$$

If no one runs for office I assume, as in Osborne and Slivinski (1996), that citizens pay a cost $x>0$, which represents the loss of utility implied by not having a decision-maker who chooses policy. ${ }^{11}$ If a citizen is indifferent between entering or not, she runs for office.

The timing of the game is as follows:

1. Nature draws the private type of each citizen,

2. citizens in $C$ simultaneously decide whether to run or not,

3. candidates pay the cost of entry $c$,

4. elections and lobbying take place as before.

The equilibrium concept analyzed in this extension of the game is the Perfect Bayesian Equilibrium (PBE), where the intuitive criterion is used as equilibrium refinement.

Let me first underline a result that would be valid for any equilibrium in a citizen-candidate model.

Proposition 4 There is no equilibrium in which citizen $i$ runs for office if she is a saint, while she does not run if she is a merchant.

The proof is in the appendix.

If a citizen is a merchant, she has larger incentives for entry, because, differently from a saint, she values the contribution of the lobby. Thus, whenever in equilibrium a citizen runs for office is she is a saint, she runs also if she is a merchant.

In order to avoid the multiplicity of equilibria, a typical feature of a citizen-candidate framework, I focus on the incentives of entry of two specific citizens: the Condorcet winner analyzed in the previous section, and the Condorcet winner of a model where there are only merchants. I denote the first candidate by $P$ and the second candidate by $S: C=\{P, S\}$. Thus $S$

\footnotetext{
${ }^{10}$ Note that, in the utility of citizen $i$, the parameter in front of the preferences for policy is normalized to 1 , implying that parameters $\rho^{i}$ and $c$ are relative to the intensity of preferences for policy.

${ }^{11}$ Osborne and Slivinski (1996) assume an infinite cost, which is a limiting case of this model.
} 
is the candidate whose merchant type in equilibrium implements the median voter's bliss point: $\frac{q^{S}+\rho q^{L}}{1+\rho}=q^{M}$. Each of these two citizens can choose to run as candidate. Voters do not directly observe their type, but they can use the entry decision of $P$ and $S$ as a signal about their responsiveness to lobbying $\rho^{t}$.

As emphasized in the previous section, candidate $P$ would be the Condorcet winner in a voting game where there is no cost of entry and all citizens run for office. Including $P$ in the set of potential candidates is therefore useful for understanding how a positive cost of entry affects her incentives for entry. Moreover, the previous section showed that lobbying is offset when there is no uncertainty on types. Indeed, if all citizens are candidates and there are either only saints or only merchants, lobbying is offset. Note that, by Proposition (4), in a model of endogenous entry there cannot be equilibria where only the saint type of a candidate runs for election. ${ }^{12}$ Thus, in order to eliminate uncertainty on types, the endogenous entry must select only merchants. The inclusion of $S$ in the set of potential candidates is therefore a natural choice, because $(S, m)$ is the Condorcet winner in a model where there are only merchants. Thus, if in the entry stage $(S, m)$ runs for election, while the saint type of $S$ does not, voters update their beliefs regarding $S$. In this case, if candidate $S$ is elected, lobbying would not affect policy, because the expected policy by $S$ would be $q^{M}$.

\section{Entry equilibrium}

Here I investigate the effect of the cost of entry on the effect of lobbying on policy. If the cost is zero, both types of each candidate run for office. Voters keep their prior beliefs on candidates' types, and elect $P$, the Condorcet winner under uncertainty: the expected equilibrium policy is biased in favor of the lobby. Hence, the objective of this section is to determine if, for some values of the cost of entry, lobbying can be offset.

I assume that the cost of entry is lower than the following threshold:

$$
\bar{c}:=k \frac{\rho^{2}}{1+\rho}\left(q^{S}-q^{L}\right)^{2}+p x+(1-p) \min \left\{x,\left(q^{S}-\frac{q^{P}+\rho q^{L}}{1+\rho}\right)^{2}\right\} .
$$

Indeed, if the cost is sufficiently high, $c>\bar{c}$, no citizen runs for office.

\footnotetext{
${ }^{12}$ For example, if the median citizen $M$ is a potential candidate, there is no equilibrium in which only her saint type runs for office, while $(M, s)$ does not run. Thus even if the saint type of the median runs and is elected, the expected implemented policy will be lower than $q^{M}$.
} 
Proposition 5 (entry-equilibrium) There is a threshold $\underline{c}$ such that, if $c>\underline{c}$ and $k \neq 0,(S, m)$ runs for office and wins the election, while $S$ does not run, if she is a saint. Lobbying does not affect policy, because the equilibrium expected policy of candidate $S$ is $q^{M}$.

The proof is in the appendix. ${ }^{13}$

Increasing the cost of entry reduces the incentives of saint types to run for office, because saints are solely policy motivated. Hence, if the cost of entry is sufficiently large, only merchants run for office: there is no effect of lobbying on policy, because voters fully anticipate the implemented policy.

\section{Extensions}

The model analyzed in this paper studies the effect of lobbying on policy under uncertainty, in a simple and stylized fashion. In this section I investigate the robustness of the results to natural extensions of the model and different assumptions on the behavior of players.

The model studies the effect of a unique lobby on policy. This can be a reasonable assumption, if there is a special interest group that dominates the lobbying market. Still, in many situations multiple special interest groups with opposing preferences intervene in the lobbying process. The model can be easily extended to case of multiple lobbies. Let me assume that there are multiple lobbies with bliss points $q^{l}, l \in L$. Lobby $l$ has the following utility:

$$
V(q, y, l)=\eta^{l} u\left(q, q^{l}\right)+y,
$$

where $\eta^{l} \geq 0$ is the relative intensity of preference for policy of lobby $l$. Parameter $\eta^{l}$ creates additional heterogeneity among lobbies: lobbies with larger $\eta$ have a larger willingness to contribute in order to move the implemented policy towards their bliss point. After being elected, politician $P$ and all lobbies bargain over policy $q$ to be implemented, and monetary transfer $R^{l}$ that lobby $l$ gives to the politician.

$\max _{q \in Q, R^{l} \geq 0, l \in L}\left[u\left(q, q^{P}\right)+\rho^{t} \sum_{l \in L} R^{l}-u\left(q^{P}, q^{P}\right)\right] \prod_{l \in L}\left[\eta^{l} u\left(q, q^{l}\right)-R^{l}-\eta^{l} u\left(q^{P}, q^{l}\right)\right]$.

\footnotetext{
${ }^{13}$ If $0<c \leq \underline{c}$, there is a pooling equilibrium where both types of candidate $P$ run for office, while $S$ does not run. In this case the expected policy is biased in favor of the lobby. For a subset of the parameters of the model, there exists also another pooling equilibrium, where both types of candidate $S$ run for office, while candidate $P$ does not run. In this case the expected policy is biased against the lobby.
} 
such that

$\left\{\begin{array}{l}u\left(q, q^{P}\right)+\rho^{t} \sum_{l \in L} R^{l}-u\left(q^{P}, q^{P}\right) \geq 0, \\ \eta^{l} u\left(q, q^{l}\right)-R^{l}-\eta^{l} u\left(q^{P}, q^{l}\right) \geq 0, l \in L .\end{array}\right.$

For simplicity I assume that all participants to the bargaining process have the same bargaining power.

The bargaining process is a game with transferable utility, therefore by Myerson (2013, p. 385), policy $q$ maximizes:

$$
u\left(q, q^{P}\right)+\rho^{P} \sum_{l \in L} \eta^{l} u\left(q, q^{l}\right) .
$$

Note that this maximization shows the equivalence of such game with a menuauction model of lobbying, where all lobbies offer truthful contributions, in the sense of Bernheim and Whinston (1986). The implemented policy is a convex combination of the politician's bliss point, and the bliss point of all lobbies, where each bliss point is weighted by the willingness $\eta$ to contribute: $q^{* P}=\frac{q^{P}+\rho^{P} \sum_{l \in L} \eta^{l} q^{l}}{1+\rho^{P} \sum_{l \in L} \eta^{l}}$. Lobbies with a larger $\eta$ have a larger influence on policy. The model analyzed in this paper includes this case, if $q^{L}$ is defined as follows: $q^{L}:=\sum_{l \in L} \eta^{l} q^{l}$. Clearly, the results of this model carry interesting implications only if $q^{L} \neq q^{M}$, which in the case of multiple lobbies means that lobbies do not perfectly compensate each other.

A second extension of the theory investigates different distortions of the policy by the lobby, other than the one analyzed in the main model. The distortion of special interest groups, in the lobbying subgame, results in an implemented policy which is a convex combination of the bliss points $q^{P}$ and $q^{L}$. As discussed in the main analysis, such distortion is in line with the literature on the topic. Moreover, the implemented policy has the realistic feature of depending on both bliss points. One might, however, argue that the implemented policy of a merchant could be the result of a different distortion of lobbying. For example, a linear shift in the direction of the lobby, or a bang-bang implemented policy where, if elected, a merchant implements the lobby's bliss point while a saint implements her bliss point. In order for the main result of this theory to hold in these situations, the variance of implemented policies needs to decrease if the politician's bliss point is closer to the lobby.

The distortion of lobbying results in a bang-bang implemented policy, if the merchant does not have preferences for policy and only values money. This case can be incorporated in the main model, by assuming $\rho \rightarrow \infty$. Note that, with such assumption, in the voting stage merchants are indifferent between all alternatives. This does not raise concerns because, by the law 
of large numbers, the distribution $f$ of non-indifferent voters' bliss points on $Q$ remains unchanged. If the distortion of lobbying results in a bang-bang implemented policy, the variance of policy is as follows: $p(1-p)\left(q^{P}-q^{L}\right)^{2}$. Variance increases in the distance $q^{P}-q^{L}$, thus the main results of the theory hold, while no comparative statics on $\rho$ can be performed.

Let me consider the case in which the distortion of lobbying is a linear shift of the policy towards $q^{L}$. This case can be incorporated in the main model by assuming that the lobby has linear utility with respect to policy: $V(q, y)=$ $-2\left|q-q^{L}\right|+y$, where 2 is a normalizing factor. With such assumption the policy implemented by a merchant is found maximizing the following expression: $-\left(q-q^{P}\right)^{2}-2 \rho\left|q-q^{L}\right|$, which leads to the following equilibrium policy: $q^{* P_{m}}=q^{P}-\rho$, if $q^{P}-\rho>q^{L}$, and $q^{* P_{m}}=q^{L}$ otherwise. Therefore, if the bliss point $q^{P}$ is far from the lobby's bliss point, i.e. $q^{P}-q^{L}>\rho$, the variance of implemented policies does not depend on the distance $q^{P}-q^{L}$ : $p(1-p) \rho^{2}$, because the policy $q^{P}$ implemented by a saint and the policy $q^{P}-\rho$ implemented by a merchant are at constant distance $\rho$. Instead, if the bliss point is sufficiently close to the lobby's bliss point, i.e. $q^{P}-q^{L} \leq \rho$, the variance of implemented policies is a function of the distance $q^{P}-q^{L}$ : $p(1-p)\left(q^{P}-q^{L}\right)^{2}$. Moreover such variance is lower than $p(1-p) \rho^{2}$. Thus variance weakly increases in the distance $q^{P}-q^{L}$. If the responsiveness to lobbying $\rho$ is sufficiently large, the variance is strictly increasing in the distance $q^{P}-q^{L}$, even for candidates whose bliss points are far from $q^{L}$. In the appendix I prove that if $\rho>\bar{\rho}$, the Condorcet winner is a candidate whose expected policy lies on the left of $q^{M}$, thus the main results of the theory hold.

\section{Discussion}

In this section I briefly discuss the implications of the model.

i. If there is uncertainty on candidates' responsiveness to lobbying, special interest groups influence policies.

This result implies that uncertainty regarding the responsiveness of politicians to lobbying is a key feature that prevents citizens from restricting the influence of special interest groups. While little attention has been devoted in the empirical literature to the relationship between uncertainty about the influence of lobbying and political outcomes, anecdotal evidence suggests that the mechanisms described in this model are at play. For example, the 2016 US democratic primaries have seen a fierce debate over voters' lack of trust 
in Hillary Clinton, in part due to her unwillingness to publish transcripts from her speeches to Wall Street firms. Voters effectively felt uncertain as to special interest groups' influence on Clinton. Recent polls carried out by The New York Times and CBS News report that between 34 and $45 \%$ of Democratic primary voters thought that special interests have much of influence on Hillary Clinton. ${ }^{14}$ As in the theory presented in this paper, the high uncertainty with regard to Clinton's responsiveness to lobbying would likely have a negative effect on her voting count in the general election and may help explain why recent polls see the two presidential candidates locked in a close contest. ${ }^{15}$

ii. If the cost of entry is sufficiently large, there is no effect of lobbying on policy.

This model shows that representative democracy can be a powerful tool in the hands of citizens in that it gives them the ability to select candidates, offsetting ex-post distortions. This ability is, however, hindered by uncertainty on policies implemented by candidates. Thus, given that merchants have higher incentives to run for office, an effective way to reduce this uncertainty on policies is to decrease saint candidates' incentives for entry. This result contributes to public debate on the supposed need for politicians who do not "sell-out" to special interest groups, suggesting that such a first-best solution may be unfeasible. ${ }^{16}$ Moreover, the comparative statics on the cost of entry can inform the debate on the cost of electoral campaigns, showing that reducing this cost can backfire, because it induces non-pandering candidates to run for office. ${ }^{17}$ Note that the cost of entry should not be directly related to the monetary cost of electoral campaigns: these costs are not usually borne directly by candidates, but rather by donors. The cost of entry includes the fatigue of running the electoral campaign and the psychological burden of being under the media spotlight. Thus for example, the length of US electoral campaigns, which can last more than a year including the primaries, can contribute to selecting candidates, reducing uncertainty on

\footnotetext{
${ }^{14}$ See http://www.nytimes.com/2015/11/13/us/politics/poll-showshillary-clinton-is-seen-as-more-likely-than-bernie-sanders-to-be-effective.html http://www.cbsnews.com/news/cbs-poll-hillary-clinton-seen-as-more-effective-uniterthan-bernie-sanders/

${ }^{15}$ See http://www.cbsnews.com/news/poll-donald-trump-up-over-hillary-clintonnationally/

${ }^{16}$ See http://www.nytimes.com/2013/10/08/opinion/politicians-for-sale.html

17 See http://www.nytimes.com/2015/04/17/upshot/how-presidential-campaignsbecame-two-year-marathons.html
} 
policy and the effect of lobbying.

\section{Conclusion}

This work studies an electoral model of lobbying, in which there is uncertainty with regard to the responsiveness of citizens to the lobby's contribution. The model demonstrates that uncertainty on the influence of special interests can lead to large effects of lobbying on policy. Moreover, it shows how this effect changes according to policy-relevant parameters, e.g. the cost of running for office.

In this paper, citizens signal their type through their entry decision. There are potentially other tools at candidates' disposal for communicating that they will not pander to lobbies. One signal could go through electoral campaign promises of no-pandering to lobbies. Unfortunately, there is an incentive for all candidates to make such promises, and lofty speeches quickly turn to cheap talk. There are other, more costly, signals that candidates can use to show voters that they will not cater to lobbies. For example, some US Presidential candidates have explicitly declined money from donors related to special interest groups. For his 2012 electoral campaign, Obama refused "Washington lobbyists or corporate interests" money. ${ }^{18}$ Further research might investigate the role of costly signals during electoral campaigns in revealing candidates' responsiveness to lobbying.

\section{Appendix}

\section{A.1 Equilibrium of the lobbying subgame}

Proof of Proposition (1)

Let me solve problem (1) for $\rho^{t}=0$. In this case the politician's surplus $u\left(q, q^{P}\right)-u\left(q^{P}, q^{P}\right)$ is negative for all $q \neq q^{P}$, and it is equal to 0 if $q=q^{P}$, because $q^{P}$ maximizes function $u\left(q, q^{P}\right)$ with respect to $q$. Therefore, the only admissible solution to the Nash bargaining is $q=q^{P}$. At the same time, if $\rho^{t}=0$, the objective function of the Nash bargaining is a decreasing function of $R$, thus the equilibrium transfer $\tilde{R}$ is equal to $=0$. Let me now prove that the Nash bargaining problem has a unique maximum, under the conditions that both surpluses are larger than zero. I then solve the system

\footnotetext{
${ }^{18}$ See http://abcnews.go.com/blogs/politics/2011/10/obama-campaign-tops-onemillion-donors/
} 
of the first order conditions for $q$ and $R$ and prove that the surpluses are both positive, computed in this solution. First, I prove that the logarithmic transformation of the function in the maximization problem is concave. I compute the Hessian matrix and prove that both second order derivatives are negative and the determinant of the Hessian matrix is positive. I define $S_{P}:=u\left(q, q^{P}\right)+\rho^{t} R-u\left(q^{P}, q^{P}\right)$ the surplus of the politician, and $S_{L}:=$ $u\left(q, q^{L}\right)-R-u\left(q^{P}, q^{L}\right)$ the surplus of the lobby. Moreover I denote by $u_{j P}$ the $j$-th derivative of function $u\left(q, q^{P}\right)$ with respect to $q$. Similarly I denote by $u_{j L}$ the $j$-th derivative of function $u\left(q, q^{L}\right)$ with respect to $q$. The first order derivative of the logarithmic transformation with respect to $q$ is the following:

$$
k \frac{u_{1 P}}{S_{P}}+(1-k) \frac{u_{1 L}}{S_{L}} .
$$

The first order derivative of the logarithmic transformation with respect to $R$ is the following:

$$
k \frac{\rho^{t}}{S_{P}}-\frac{1-k}{S_{L}}
$$

The second order derivative of the logarithmic transformation with respect to $q$ is the following:

$$
k \frac{S_{P} u_{2 P}-u_{1 P}^{2}}{S_{P}^{2}}+(1-k) \frac{S_{L} u_{2 L}-u_{1 L}^{2}}{S_{L}^{2}} .
$$

$u_{2 P}$ and $u_{2 L}$ are negative, thus quantity (3) is negative. The second order derivative of the logarithmic transformation with respect to $R$ is the following:

$$
-\frac{k\left(\rho^{t}\right)^{2}}{S_{P}^{2}}-\frac{1-k}{S_{L}^{2}}
$$

which is negative as well. The cross derivative is the following:

$$
-k \rho^{t} \frac{u_{1 P}}{S_{P}^{2}}+(1-k) \frac{u_{1 L}}{S_{L}^{2}} .
$$


The determinant is the following:

$$
\begin{array}{r}
-k^{2}\left(\rho^{t}\right)^{2} \frac{S_{P} u_{2 P}-u_{1 P}^{2}}{S_{P}^{4}}-(1-k) k \frac{S_{P} u_{2 P}-u_{1 P}^{2}+\left(\rho^{t}\right)^{2} S_{L} u_{2 L}-\left(\rho^{t}\right)^{2} u_{1 L}^{2}}{S_{L}^{2} S_{P}^{2}} \\
-(1-k)^{2} \frac{S_{L} u_{2 L}-u_{1 L}^{2}}{S_{L}^{4}}-\frac{k^{2}\left(\rho^{t}\right)^{2} u_{1 P}^{2}}{S_{P}^{4}}-\frac{(1-k)^{2} u_{1 L}^{2}}{S_{L}^{4}}+\frac{2 k(1-k) \rho^{t} u_{1 P} u_{1 L}}{S_{L}^{2} S_{P}^{2}}= \\
-k^{2}\left(\rho^{t}\right)^{2} \frac{u_{2 P}}{S_{P}^{3}}-(1-k) k \frac{S_{P} u_{2 P}-u_{1 P}^{2}+\left(\rho^{t}\right)^{2} S_{L} u_{2 L}-\left(\rho^{t}\right)^{2} u_{1 L}^{2}}{S_{L}^{2} S_{P}^{2}} \\
-(1-k)^{2} \frac{u_{2 L}}{S_{L}^{3}}+\frac{2 k(1-k) \rho^{t} u_{1 P} u_{1 L}}{S_{L}^{2} S_{P}^{2}} .
\end{array}
$$

All addenda in the last expression are positive, hence the determinant is positive. Let me solve problem (1) for $\rho^{t} \neq 0$. The transfer $R$ is computed, solving the maximization (1), under the condition $R \geq 0$ and $q \in Q$. I take the logarithmic transformation of the function in the maximization problem (1) and deriving with respect to $R$ the following first order condition is found: $\frac{k \rho^{t}}{u\left(q, q^{P}\right)+\rho^{t} R-u\left(q^{P}, q^{P}\right)}-\frac{1-k}{u\left(q, q^{L}\right)-R-u\left(q^{P}, q^{L}\right)}=0$, which brings the following solution: $\tilde{R}(q)=k\left[u\left(q, q^{L}\right)-u\left(q^{P}, q^{L}\right)\right]+(1-k) \frac{1}{\rho^{t}}\left[u\left(q^{P}, q^{P}\right)-u\left(q, q^{P}\right)\right]$. Deriving the same logarithmic transformation with respect to $q$ the following first order condition is found: $-2 k\left[u\left(q, q^{L}\right)-R-u\left(q^{P}, q^{L}\right)\right]\left(q-q^{P}\right)-$ $2(1-k)\left[u\left(q, q^{P}\right)+\rho^{t} R-u\left(q^{P}, q^{P}\right)\right]\left(q-q^{L}\right)=0$. Substituting $R=\tilde{R}$ in expressions $\left[u\left(q, q^{L}\right)-R-u\left(q^{P}, q^{L}\right)\right]$ and $\left[u\left(q, q^{P}\right)+\rho^{t} R-u\left(q^{P}, q^{P}\right)\right]$ I obtain respectively $(1-k)\left[1 / \rho^{t} u\left(q, q^{P}\right)+u\left(q, q^{L}\right)-1 / \rho^{t} u\left(q^{P}, q^{P}\right)-u\left(q^{P}, q^{L}\right)\right]$ and $k \rho^{t}\left[1 / \rho^{t} u\left(q, q^{P}\right)+u\left(q, q^{L}\right)-1 / \rho^{t} u\left(q^{P}, q^{P}\right)-u\left(q^{P}, q^{L}\right)\right]$, which can be substituted in the first order condition for $q$ :

$$
\begin{array}{r}
-2 k(1-k)\left[1 / \rho^{t} u\left(q, q^{P}\right)+u\left(q, q^{L}\right)-1 / \rho^{t} u\left(q^{P}, q^{P}\right)-\right. \\
\left.u\left(q^{P}, q^{L}\right)\right]\left[q-q^{P}+\rho^{t}\left(q-q^{L}\right)\right]=0 .
\end{array}
$$

Either expression $E:=\left[1 / \rho^{t} u\left(q, q^{P}\right)+u\left(q, q^{L}\right)-1 / \rho^{t} u\left(q^{P}, q^{P}\right)-u\left(q^{P}, q^{L}\right)\right]$ or $q-q^{P}+\rho^{t}\left(q-q^{L}\right)$ are zero. If $E=0$, given that $(1-k) E$ and $k \rho^{t} E$ are the surpluses respectively of the lobby and the politician, both assume value 0 . If $q-q^{P}+\rho^{t}\left(q-q^{L}\right)=0$, the solution would be $q^{* P_{t}}=\left(q^{P}+\rho^{t} q^{L}\right) /\left(1+\rho^{t}\right)$. If I substitute $q^{* P_{t}}$ in $E$, it becomes $\rho^{t} /\left(1+\rho^{t}\right)\left(q^{P}-q^{L}\right)^{2}$, which is positive, implying that both surpluses are positive. Hence solving for $E=0$ cannot bring to a maximizer. Therefore $q^{* P_{t}}$ and $\tilde{R}\left(q^{* P_{t}}\right)$ are respectively the policy and the transfer that solve the Nash bargaining problem. 
The computation of politician $P$ 's indirect utility

The indirect utility of politician $P$ is computed as follows:

$$
\begin{array}{r}
U\left(q^{* P}, \tilde{R}, P\right)=u\left(q^{* P}, q^{P}\right)+ \\
\rho^{t} k\left[u\left(q^{* P_{t}}, q^{L}\right)-u\left(q^{P}, q^{L}\right)\right]-(1-k) u\left(q^{* P}, q^{P}\right)= \\
k\left\{u\left(q^{* P}, q^{P}\right)+\rho^{t}\left[u\left(q^{* P_{t}}, q^{L}\right)-u\left(q^{P}, q^{L}\right)\right]\right\}= \\
k\left\{-\left(\frac{\left(1+\rho^{t}\right) q^{P}-q^{P}-\rho^{t} q^{L}}{1+\rho^{t}}\right)^{2}+\right. \\
\left.\rho^{t}\left[-\left(\frac{\left(1+\rho^{t}\right) q^{L}-q^{P}-\rho^{t} q^{L}}{1+\rho^{t}}\right)^{2}+\left(q^{P}-q^{L}\right)^{2}\right]\right\}= \\
\left(-\rho^{t}-1+\left(1+\rho^{t}\right)^{2}\right) \frac{k \rho^{t}}{\left(1+\rho^{t}\right)^{2}}\left(q^{P}-q^{L}\right)^{2}= \\
\frac{k\left(\rho^{t}\right)^{2}}{1+\rho^{t}}\left(q^{P}-q^{L}\right)^{2} .
\end{array}
$$

\section{A.2 Equilibrium of the voting subgame}

\section{The computation of $\operatorname{Var}^{P}$}

The variance of implemented policies can be computed as follows:

$$
\begin{gathered}
\mathbb{E}\left(q^{* P}\right)^{2}=(1-p)\left(\frac{q^{P}+\rho q^{L}}{1+\rho}\right)^{2}+p\left(q^{P}\right)^{2}, \\
\mathbb{E}^{2}\left(q^{* P}\right)=\left((1-p) \frac{q^{P}+\rho q^{L}}{1+\rho}+p q^{P}\right)^{2}, \\
\operatorname{Var}^{P}=\mathbb{E}\left(q^{* P}\right)^{2}-\mathbb{E}^{2}\left(q^{* P}\right)= \\
p(1-p)\left(\frac{q^{P}+\rho q^{L}}{1+\rho}\right)^{2}+p(1-p)\left(q^{P}\right)^{2}-2 p(1-p) q^{P} \frac{q^{P}+\rho q^{L}}{1+\rho}= \\
\frac{p(1-p)}{(1+\rho)^{2}}\left\{\left(q^{P}\right)^{2}+\rho^{2}\left(q^{L}\right)^{2}+2 \rho q^{P} q^{L}+(1+\rho)^{2}\left(q^{P}\right)^{2}\right. \\
\left.-2(1+\rho)\left(q^{P}\right)^{2}-2(1+\rho) \rho q^{P} q^{L}\right\}= \\
\frac{\rho^{2} p(1-p)}{(1+\rho)^{2}}\left(q^{P}-q^{L}\right)^{2} .
\end{gathered}
$$




\section{Proof of Proposition (2)}

In the voting subgame the Condorcet winner is the candidate with a bliss point that solves the following problem:

$$
\max _{q^{P} \in[0,1]}-\left(q^{M}-\bar{q}^{P}\right)^{2}-v\left(q^{P}-q^{L}\right)^{2}
$$

where $\bar{q}^{P}=\frac{1+\rho p}{1+\rho} q^{P}+\frac{\rho(1-p)}{1+\rho} q^{L}$. The first order condition is as follows:

$$
\begin{array}{r}
+\left(q^{M}-\bar{q}^{P}\right)\left(\frac{1+\rho p}{1+\rho}\right)-v\left(q^{P}-q^{L}\right)=0 \\
q^{P}=\frac{\frac{1+\rho p}{1+\rho} q^{M}+\left(v-\rho(1-p) \frac{1+\rho p}{(1+\rho)^{2}}\right) q^{L}}{\left(\frac{1+\rho p}{1+\rho}\right)^{2}+v}= \\
\frac{(1+\rho p)(1+\rho) q^{M}-\rho(1-p) q^{L}}{(1+\rho p)^{2}+\rho^{2} p(1-p)} .
\end{array}
$$

In order to avoid a corner solution, $q^{P}$ should be in the following interval: $q^{P} \in[0,1]$. The difference $q^{P}-q^{M}$ is positive, thus $q^{P}$ is larger than or equal to 0 :

$$
\begin{aligned}
q^{P}-q^{M} \geq 0 & \Leftrightarrow \\
(1+\rho p)(1+\rho) q^{M}-\rho(1-p) q^{L}-(1+\rho p)^{2} q^{M}-\rho^{2} p(1-p) q^{M} \geq 0 & \Leftrightarrow \\
(1+\rho p)(1+\rho-1-\rho p) q^{M}-\rho(1-p) q^{L}-\rho^{2} p(1-p) q^{M} \geq 0 & \Leftrightarrow \\
\rho(1-p)(1+\rho p-\rho p) q^{M}-\rho(1-p) q^{L} \geq 0 & \Leftrightarrow \\
\rho(1-p)\left(q^{M}-q^{L}\right) & \geq 0 .
\end{aligned}
$$

Moreover $q^{P}$ is lower than or equal to 1 :

$$
\begin{array}{r}
q^{P} \leq 1 \Leftrightarrow \\
(1+\rho p)(1+\rho) q^{M}-\rho(1-p) q^{L} \leq(1+\rho p)^{2}+\rho^{2} p(1-p) \Leftrightarrow \\
(1+\rho) q^{M}+(1+\rho) \rho p q^{M}-\rho q^{L}+\rho p q^{L} \leq 1+2 \rho p+\rho^{2} p \Leftrightarrow \\
\rho p \geq \frac{(1+\rho) q^{M}-1-\rho q^{L}}{(1+\rho)\left(1-q^{M}\right)+1-q^{L}} .
\end{array}
$$

The denominator is positive. The numerator is instead non positive, because $\rho \leq \frac{1-q^{M}}{q^{M}-q^{L}}$, as assumed by Inequality (2). Therefore the last inequality is satisfied. 
The equilibrium expected policy is computed, substituting in $\bar{q}^{P}$ the solution (4) for the Condorcet winner $q^{P}$ :

$$
\begin{array}{r}
\bar{q}^{P}=\frac{\left(\frac{1+\rho p}{1+\rho}\right)^{2} q^{M}+\left(\frac{1+\rho p}{1+\rho} v-\frac{\rho(1-p)}{1+\rho}\left(\frac{1+\rho p}{1+\rho}\right)^{2}\right) q^{L}}{\left(\frac{1+\rho p}{1+\rho}\right)^{2}+v} \\
+\frac{\frac{\rho(1-p)}{1+\rho}\left(\frac{1+\rho p}{1+\rho}\right)^{2} q^{L}+\frac{\rho(1-p)}{1+\rho} v q^{L}}{\left(\frac{1+\rho p}{1+\rho}\right)^{2}+v}= \\
\frac{(1+\rho p)^{2} q^{M}+\rho^{2} p(1-p) q^{L}}{(1+\rho p)^{2}+\rho^{2} p(1-p)} .
\end{array}
$$

The equilibrium expected policy is lower than $q^{M}$, because it is a convex combination of $q^{L}$ and $q^{M}$, therefore it lies in between the two bliss points.

\section{Proof of Proposition (3)}

The sign of the derivative of the expected policy with respect to the responsiveness to lobbying of merchant types is computed as follows:

$$
\begin{array}{r}
\frac{\partial \bar{q}^{P}}{\partial \rho}<0 \Leftrightarrow \\
\left((1+\rho p)^{2}+p(1-p) \rho^{2}\right)\left(2(1+\rho p) p q^{M}+2 \rho p(1-p) q^{L}\right)- \\
\left((1+\rho p)^{2} q^{M}+p(1-p) \rho^{2} q^{L}\right)(2(1+\rho p) p+2 \rho p(1-p))<0 \Leftrightarrow \\
\left(q^{M}-q^{L}\right)\left(\rho^{2} p^{2}(1-p)(1+\rho p)-\rho p(1-p)(1+\rho p)^{2}\right)<0 \Leftrightarrow \\
-\left(q^{M}-q^{L}\right) \rho p(1-p)(1+\rho p)<0 .
\end{array}
$$

The last inequality is satisfied. Hence the derivative of $\bar{q}^{P}$ with respect to $\rho$ is negative. If $\rho$ increases, the distortion of lobbying $q^{M}-\bar{q}^{P}$ increases.

The sign of the derivative of the expected policy with respect to probability of types is computed as follows:

$$
\begin{array}{r}
\frac{\partial \bar{q}^{P}}{\partial p} \geq 0 \Leftrightarrow \\
\left(2(1+\rho p) \rho q^{M}+\rho^{2}(1-2 p) q^{L}\right)\left((1+\rho p)^{2}+\rho^{2} p(1-p)\right)- \\
\left((1+\rho p)^{2} q^{M}+\rho^{2} p(1-p) q^{L}\right)\left(2 \rho(1+\rho p)+\rho^{2}(1-2 p)\right) \geq 0 \Leftrightarrow \\
\left(q^{M}-q^{L}\right) \rho^{2}(1+\rho p)(2 \rho p(1-p)-(1+\rho p)(1-2 p)) \geq 0 \Leftrightarrow p \geq \frac{1}{2+\rho} .
\end{array}
$$


Thus, the effect $p$ on $\bar{q}^{P}$ is non-monotonic. If $p<\bar{p}:=\frac{1}{1+2 \rho}$, increasing $p$ increases the distortion of lobbying $q^{M}-\bar{q}^{P}$. If $p \geq \bar{p}:=\frac{1}{1+2 \rho}$, increasing $p$ reduces the distortion of lobbying.

Here I compute the effect of $\rho$ and $p$ on the median voter's welfare. By the envelope theorem, when deriving the median voter's indirect utility with respect to the parameters of the model, I do not take into account the effect of the parameters on the Condorcet winner's bliss point $q^{P}$ :

$$
\begin{array}{r}
\frac{\partial}{\partial \rho} \mathbb{E}\left(u\left(q^{* P}, q^{M}\right)\right)=2\left(q^{M}-\bar{q}^{P}\right) \frac{\partial \bar{q}^{P}}{\partial \rho}-\frac{\partial v}{\partial \rho}\left(q^{P}-q^{L}\right)^{2}= \\
\frac{2\left(q^{M}-\bar{q}^{P}\right)}{(1+\rho)^{2}}\left(\left(p q^{P}+(1-p) q^{L}\right)(1+\rho)-(1+\rho p) q^{P}-\rho(1-p) q^{L}\right)- \\
\frac{\left(q^{P}-q^{L}\right)^{2}}{(1+\rho)^{4}}\left(2 \rho p(1-p)(1+\rho)^{2}-2 \rho^{2}(1+\rho) p(1-p)\right)= \\
-\frac{2\left(q^{M}-\bar{q}^{P}\right)}{(1+\rho)^{2}}(1-p)\left(q^{P}-q^{L}\right)-\frac{\left(q^{P}-q^{L}\right)^{2}}{(1+\rho)^{4}} 2 \rho(1+\rho) p(1-p)<0
\end{array}
$$

Thus, voter welfare decreases with $\rho$.

$$
\begin{aligned}
\frac{\partial}{\partial p} \mathbb{E}\left(u\left(q^{* P}, q^{M}\right)\right)= & 2\left(q^{M}-\bar{q}^{P}\right) \frac{\rho}{1+\rho}\left(q^{P}-q^{L}\right)-\frac{\rho^{2}}{(1+\rho)^{2}}(1-2 p)\left(q^{P}-q^{L}\right)^{2}= \\
& \frac{\rho}{1+\rho}\left(q^{P}-q^{L}\right)\left(2\left(q^{M}-\bar{q}^{P}\right)-\frac{\rho}{1+\rho}(1-2 p)\left(q^{P}-q^{L}\right)\right) .
\end{aligned}
$$

I compute the following expressions:

$$
\begin{gathered}
q^{M}-\bar{q}^{P}=\frac{\rho^{2} p(1-p)\left(q^{M}-q^{L}\right)}{(1+\rho p)^{2}+\rho^{2} p(1-p)}, \\
q^{P}-q^{L}=\frac{(1+\rho p)(1+\rho) q^{M}-(1+\rho p)(\rho(1-p)+1+\rho p) q^{L}}{(1+\rho p)^{2}+\rho^{2} p(1-p)}= \\
\frac{(1+\rho p)(1+\rho)\left(q^{M}-q^{L}\right)}{(1+\rho p)^{2}+\rho^{2} p(1-p)} .
\end{gathered}
$$

Substituting these two expressions in the derivative of the median voter's welfare with respect to $p$, I obtain:

$$
\frac{\rho^{2}\left(q^{P}-q^{L}\right)\left(q^{M}-q^{L}\right)}{(1+\rho)\left((1+\rho p)^{2}+\rho^{2} p(1-p)\right)}(2 \rho p(1-p)-(1+\rho p)(1-2 p)) .
$$




$$
\begin{aligned}
& \frac{\partial}{\partial \rho} \mathbb{E}\left(u\left(q^{* P}, q^{M}\right)\right) \geq 0 \Leftrightarrow \\
& 2 \rho p(1-p)-(1+\rho p)(1-2 p) \geq 0 \Leftrightarrow \\
& \rho p+2 p-1 \geq 0 \Leftrightarrow \\
& p \geq \frac{1}{2+\rho} .
\end{aligned}
$$

Thus, median voter's welfare and the distortion of lobbying have the same comparative statics.

\section{A.3 Endogenous entry}

\section{Proof of Proposition (4)}

If citizen $(i, s)$ runs for office and wins the election, her utility is 0 , because she implements her bliss point. If $(i, m)$ runs and wins the election, her utility is $k \frac{\left(\rho^{t}\right)^{2}}{1+\rho^{t}}\left(q^{P}-q^{L}\right)^{2}>0$, because she panders to the lobby and receives its contribution. If citizen $i$ runs for office but loses, or if she does not run, her utility does not depend on her type. Hence, merchants have larger incentive to run for office than saints. There can be no equilibrium where $(i, s)$ runs for office and $(i, m)$ does not, because $(i, m)$ would deviate and run, increasing her utility.

\section{Proof of Proposition (5)}

Let me consider $c>\underline{c}:=p x+(1-p) \max \left\{x,\left(q^{S}-\frac{q^{P}+\rho q^{L}}{1+\rho}\right)^{2}\right\}$. I will prove that there is a unique equilibrium that survives the intuitive criterion refinement. In this equilibrium $(S, m)$ runs for office, while $(S, s)$ does not run.

First, let me analyze the existence of separating equilibria. There are no separating equilibria where saints run for office, as implied by proposition (4). Let me analyze the conditions under which $(P, m)$ runs for office, $(P, s)$ does not run, and citizen $S$ does not run. Given that $P$ is the unique candidate in this equilibrium, voters elect her. Voters update their beliefs on her type, assigning probability 1 to $(P, m)$. The median voter receives utility $-\left(q^{M}-\right.$ $\left.\frac{q^{P}+\rho q^{L}}{1+\rho}\right)^{2}$ from the election of $P$. Let me assume that all the conditions for this equilibrium are satisfied, and let me prove that, nonetheless, this equilibrium does not satisfy the intuitive criterion. Note that running for 
office is equilibrium dominated for $(S, s)$ :

$$
-p x-(1-p)\left(q^{S}-\frac{q^{P}+\rho q^{L}}{1+\rho}\right)^{2}>0-c .
$$

If $(S, s)$ does not run, with probability $p$ candidate $(P, s)$ is drawn and she does not run, thus cost $x$ is paid. With probability $(1-p)$ candidate $(S, m)$ is drawn and citizen $S$ has disutility $\left(q^{S}-\frac{q^{P}+\rho q^{L}}{1+\rho}\right)^{2}$. If she runs, she pays the cost of entry and in the best case scenario she wins against $P$. She implements her bliss point, receiving utility 0 from policy. The previous inequality is satisfied, if $c>\underline{c}$. By the intuitive criterion, if voters observe the entry of $S$, they assign probability 1 to candidate $(S, m)$. Voters elect $(S, m)$, because she delivers the largest utility that the median citizen can achieve. Candidate $(S, m)$ deviates and runs for office, because

$$
k \frac{\rho^{2}}{1+\rho}\left(q^{S}-q^{L}\right)^{2}-c \geq-p x-(1-p)\left(q^{S}-\frac{q^{P}+\rho q^{L}}{1+\rho}\right)^{2} .
$$

The previous inequality is satisfied, because $c \leq \bar{c}$. Therefore the intuitive criterion eliminates this equilibrium.

Let me consider the conditions under which $(S, m)$ runs for office, while $(S, s)$ does not. If voters observe the entry of candidate $S$, they update their beliefs on her type, assigning probability 1 to $(S, m)$. The expected equilibrium policy is $q^{M}$. If voters observe the entry of candidate $P$, for any equilibrium and out of equilibrium beliefs on $P$, candidate $S$ is elected, because her implemented policy $q^{M}$ maximizes the utility of the median. Thus, the equilibrium outcome is independent on beliefs about $P$. Therefore an equilibrium where $(S, m)$ runs for office, while $(S, s)$ does not, satisfies the intuitive criterion refinement. Candidate $(S, m)$ runs for office if the utility she receives from entry is larger than the utility from staying out of the race. As will be clear below, depending on the parameters of the model, either $P$ does not run in equilibrium against $S$, or only $(P, m)$ runs against $(S, m)$. In the first case $(S, m)$ runs if the following inequality is satisfied:

$$
k \frac{\rho^{2}}{1+\rho}\left(q^{S}-q^{L}\right)^{2}-c \geq-x .
$$

This inequality is satisfied, because $c \leq \bar{c}$. In the second case $(S, m)$ runs if the following inequality is satisfied:

$$
k \frac{\rho^{2}}{1+\rho}\left(q^{S}-q^{L}\right)^{2}-c \geq-p x-(1-p)\left(q^{S}-\frac{q^{P}+\rho q^{L}}{1+\rho}\right)^{2} .
$$


Indeed, with probability $p(P, m)$ is not drawn, therefore if $S$ does not run she pays cost $x$. With probability $1-p(P, m)$ is drawn, therefore if $S$ does not run she suffers disutility $\left(q^{S}-\frac{q^{P}+\rho q^{L}}{1+\rho}\right)^{2}$. This inequality is satisfied, because $c \leq \bar{c}$. Candidate $(S, s)$ does not run, because the utility she receives from entry is lower than the utility from staying out of the race:

$$
0-c<-x
$$

If she runs, she is alone in the race. $(S, s)$ wins the election and implements her bliss point, receiving utility 0 from policy. In order to run she pays the cost $c$. If she does not run, cost $x$ is paid. The previous inequality is satisfied, if $c>\underline{c}$. $P$ wins the election, only if $(S, m)$ is not drawn by Nature. Citizen $(P, s)$ does not run for office if the following inequality is satisfied:

$$
-(1-p)\left(q^{P}-q^{M}\right)^{2}-p x>-(1-p)\left(q^{P}-q^{M}\right)^{2}-0-c .
$$

If $(P, s)$ does not run for office, with probability $p$ she pays the cost $x$, because there is no candidate in the race. If she runs for office she pays the cost $c$ and with probability $p$ she is alone in the race, in which case she implements her bliss point. The previous inequality reduces to $c>p x$, which is satisfied, if $c>\underline{c}$. Thus $(P, s)$ does not run. Candidate $(P, m)$ runs if

$$
-p x \leq p k \frac{\rho^{2}}{1+\rho}\left(q^{P}-q^{L}\right)^{2}-c .
$$

$(P, m)$ has a larger incentive to run, because she values the contribution $R$. The previous inequality reduces to $c / p \leq x+k \frac{\rho^{2}}{1+\rho}\left(q^{P}-q^{L}\right)^{2}$. The results can be summarized as follows: if $c>\underline{c}$ candidate $(S, m)$ runs, while $(S, s)$ does not. If drawn $(S, m)$ wins the election and implements the median voter's bliss point. If $\underline{c}<c \leq p x+p k \frac{\rho^{2}}{1+\rho}\left(q^{P}-q^{L}\right)^{2}$ candidate $(P, m)$ runs but loses the election, if $(S, m)$ is drawn. If $c \geq p x+p k \frac{\rho^{2}}{1+\rho}\left(q^{P}-q^{L}\right)^{2}$ candidate $(P, m)$ does not run. Note that the interval $[\underline{c}, \bar{c}]$ is not empty if and only if $k \neq 0$. Thus this equilibrium exists if $c>\underline{c}$ and $k \neq 0$.

Let me finally analyze the possibility of pooling equilibria. There are five possible pooling equilibria. In the first case, both types of $S$ run for office, while $P$ does not run. This cannot be an equilibrium, because $(S, s)$ deviates, not running for election, as Inequality (6) shows. For the same reason, there is no equilibrium where both types of $P$ run for office, while $S$ does not run. In the third case, both types of each candidate run for office. $P$ is elected, because she is the Condorcet winner of an election where all types run. $S$ deviates, because she pays cost $c$ without changing the equilibrium outcome. 
In the fourth case, both types of $S$ run for office, $(P, m)$ runs for office and $(P, s)$ does not run. $(S, s)$ would deviate, not running, because Inequality (5) shows that, even if $(S, s)$ wins against $(P, m)$, she prefers to stay out of the race. In the fifth case, both types of $P$ run for office, $(S, m)$ runs for office and $(S, s)$ does not run. $(P, s)$ would deviate, not running, as Inequality (7) shows. There are no pooling equilibria where both types of a candidate run for office, while only the saint type of her opponent runs, as proven by Proposition (4). Therefore the equilibrium analyzed in this proof is unique.

\section{A.4 Extensions}

\section{Different distortion of lobbies. Proof}

This paragraph proves that, in the case of a linear distortion of lobbying, if $\rho>\bar{\rho}$, the equilibrium expected policy is on the left of $q^{M}$. First of all, let me find the Condorcet winner, assuming that the Condorcet winner is such that $q^{A}-q^{L} \leq \rho$. In this case $(A, m)$ implements $q^{L}$.

$$
\max _{q^{A}}-\left(q^{M}-p q^{A}-(1-p) q^{L}\right)^{2}-p(1-p)\left(q^{A}-q^{L}\right)^{2} .
$$

The first order condition is as follows:

$$
+\left(q^{M}-p q^{A}-(1-p) q^{L}\right) p-p(1-p)\left(q^{A}-q^{L}\right)=0,
$$

which leads to the following solution: $q^{A}=q^{M}$. In this case the expected policy is on the left of the median voter's bliss point: $\bar{q}^{A}=p q^{M}+(1-p) q^{L}<$ $q^{M}$. The indirect utility of the median voter, by voting for $A$, is as follows:

$$
\begin{array}{r}
-\left(q^{M}-p q^{M}-(1-p) q^{L}\right)^{2}-p(1-p)\left(q^{M}-q^{L}\right)^{2}= \\
-(1-p)\left(q^{M}-q^{L}\right)^{2} .
\end{array}
$$

Let me find the Condorcet winner, assuming that the Condorcet winner is such that $q^{B}-q^{L}>\rho$. In this case $(B, m)$ implements $q^{B}-\rho$.

$$
\max _{q^{B}}-\left(q^{M}-p q^{B}-(1-p)\left(q^{B}-\rho\right)\right)^{2}-p(1-p) \rho^{2} .
$$

The first order condition is as follows:

$$
q^{M}-p q^{B}-(1-p)\left(q^{B}-\rho\right)=0,
$$

which leads to the following solution: $q^{B}=q^{M}+(1-p) \rho$. The expected policy is the median voter's bliss point: $\bar{q}^{B}=q^{M}+(1-p) \rho-(1-p) \rho=q^{M}$. The indirect utility of the median voter, by voting for $B$, is as follows: $-p(1-p) \rho^{2}$. 
Two conditions must be valid, for the equilibrium expected policy to be on the left of $q^{M}$. First, candidate $A$ 's bliss point must satisfy the following inequality: $q^{M}-q^{L} \leq \rho$. Secondly, the utility of the median voter must be larger by voting for $A$, than by voting for $B$ :

$$
\begin{array}{r}
-p(1-p) \rho^{2}<-(1-p)\left(q^{M}-q^{L}\right)^{2} \Leftrightarrow \\
\rho>\frac{q^{M}-q^{L}}{\sqrt{p}} .
\end{array}
$$

Also $B$ 's bliss point has to satisfy the following inequality: $q^{M}+(1-p) \rho-q^{L}>$ $\rho \Rightarrow \rho<\frac{q^{M}-q^{L}}{p}$. This inequality creates an upper bound on $\rho$. Note however, that if $\rho \geq \frac{q^{M}-q^{L}}{p}$, the Condorcet winner in the set of candidates $R$ such that $q^{R}-q^{L}>\rho$ is $q^{R}=q^{L}+\rho$, and her expected policy is $p\left(q^{L}+\rho\right)+(1-$ p) $\left(q^{L}+\rho-\rho\right)=q^{L}+p \rho>q^{M}$. The median voter would compare $A$, the Condorcet winner in the set of candidates $P$ such that $q^{P}-q^{L} \leq \rho$, with the Condorcet winner in the set of candidates $R$ such that $q^{R}-q^{L}>\rho$. The latter necessarily gives to the median voter lower utility than $-p(1-p) \rho^{2}$, because her expected policy is larger than $q^{M}$. Given that $\frac{q^{M}-q^{L}}{p}>\frac{q^{M}-q^{L}}{\sqrt{p}}$, if $\rho$ is such that the Condorcet winner in the set of candidates $R$ (such that $q^{R}-q^{L}>\rho$ ) gives lower utility to the median than the utility given by $B$, then $\rho$ is also such that the median votes for $A$ over $B$. Thus by transitivity the median votes for $A$ over $R$ : the Condorcet winner is still $A$. Hence, if $\rho>\bar{\rho}:=\frac{q^{M}-q^{L}}{\sqrt{p}}$, the equilibrium expected policy is on the left of the median voter's bliss point.

\section{References}

Ansolabehere, Stephen, John M. de Figueiredo and James M. Snyder, Jr. 2003. "Why is There so Little Money in US Politics?" Journal of Economic Perspectives 17(1):105-130.

Ashworth, Scott. 2006. "Campaign finance and voter welfare with entrenched incumbents." American Political Science Review 100(01):55-68.

Bernheim, B. Douglas and Micheal D. Whinston. 1986. "Menu Auctions, Resource Allocation, and Economic Influence." The Quarterly Journal of Economics 101(1):1-32. 
Besley, Timothy and Stephen Coate. 1997. "An Economic Model of Representative Democracy." The Quarterly Journal of Economics 112(1):85-114.

Besley, Timothy and Stephen Coate. 2001. "Lobbying and welfare in a representative democracy." The Review of Economic Studies 68(1):67-82.

Blanes i Vidal, Jordi, Mirko Draca and Christian Fons-Rosen. 2012. "Revolving door lobbyists." The American Economic Review 102(7):3731-3748.

Bronars, Stephen G and John R. Lott, Jr. 1997. "Do Campaign Donations Alter How a Politician Votes? Or, Do Donors Support Candidates Who Value the Same Things That They Do?" The Journal of Law and Economics 40(2):317-350.

Callander, Steven. 2008. "Political motivations." The Review of Economic Studies 75(3):671-697.

Coate, Stephen. 2004. "Pareto-improving campaign finance policy." American Economic Review pp. 628-655.

Eggers, Andrew C and Jens Hainmueller. 2014. "Political capital: Corporate connections and stock investments in the US congress, 2004-2008." Quarterly Journal of Political Science pp. 2012-26.

Felli, Leonardo and Antonio Merlo. 2006. "Endogenous Lobbying." Journal of the European Economic Association 4(1):180-215.

Felli, Leonardo and Antonio Merlo. 2007. "If you cannot get your friends elected, lobby your enemies." Journal of the European Economic Association 5(2-3):624-635.

Grosser, Jens and Thomas R Palfrey. 2014. "Candidate entry and political polarization: An antimedian voter theorem." American Journal of Political Science 58(1):127-143.

Grossman, Gene M. and Elhanan Helpman. 1994. "Protection for Sale." The American Economic Review 84(4):833-850.

Luechinger, Simon and Christoph Moser. 2014. "The value of the revolving door: Political appointees and the stock market." Journal of Public Economics 119:93-107.

Myerson, Roger B. 2013. Game theory. Harvard University Press. 
Osborne, Martin J. and Al Slivinski. 1996. "A Model of Political Competition with Citizen-Candidates." The Quarterly Journal of Economics 111(1):6596.

Prat, Andrea. 2002a. "Campaign advertising and voter welfare." The Review of Economic Studies 69(4):999-1017.

Prat, Andrea. 2002b. "Campaign spending with office-seeking politicians, rational voters, and multiple lobbies." Journal of Economic Theory 103(1):162-189.

Roberti, Paolo. 2014. Lobbying in a multidimensional policy space with salient issues. Quaderni - Working Paper DSE Bologna.

Sobbrio, Francesco. 2011. "Indirect lobbying and media bias." Quarterly Journal of Political Science 6:3-4.

Stratmann, Thomas. 2002. "Can Special Interests Buy Congressional Votes? Evidence from Financial Services Legislation." Journal of law and economics 45(2):345-373.

Stratmann, Thomas. 2005. "Some talk: money in politics. A (partial) review of the literature." Public Choice 124(1):135-156.

Wright, John R. 1990. "Contributions, lobbying, and committee voting in the US House of Representatives." The American Political Science Review 84(2):417-438. 


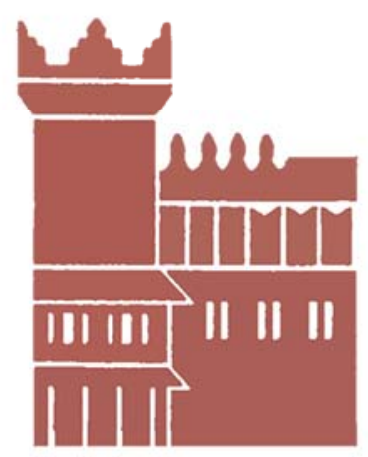

Alma Mater Studiorum - Università di Bologna DEPARTMENT OF ECONOMICS

Strada Maggiore 45

40125 Bologna - Italy

Tel. +39051 2092604

Fax +390512092664

http://www.dse.unibo.it 